\title{
DIMENSÕES TEÓRICAS E PRÁTICAS DA QUALIDADE DA DEMOCRACIA
}

Maria Salete Souza de Amorim Rodrigo Rodrigues Dias

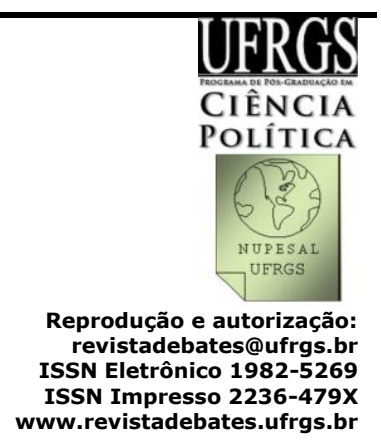

\section{Resumo}

$\mathrm{O}$ artigo tem como objetivo situar o Brasil no atual debate sobre a qualidade da democracia, problematizando o tipo de democracia que tem se configurado na América Latina, levando em consideração dimensões de apoio e satisfação com a democracia, e confiança nas instituições políticas. Para tanto, realizou-se revisão teórica sobre a concepção de democracia e foram utilizados dados de pesquisas disponibilizadas pelo Latinobarômetro para sondar variáveis que podem explicar o ranking das democracias contemporâneas no âmbito de sua qualidade. Os resultados mostraram que, do ponto de vista da institucionalidade política, a qualidade da democracia no Brasil tem sido avaliada positivamente, mas do ponto de vista dos seus conteúdos e da efetividade de seus resultados, a democracia ainda não alcançou medidas qualitativas mais substantivas.

Palavras-chave: Democracia; Qualidade da Democracia; Apoio; Satisfação; Confiança.

\begin{abstract}
The article aims to situate the current debate in Brazil about the quality of democracy, questioning the kind of democracy institutionalized in Latin America, taking into account dimensions of support and satisfaction with democracy and trust in political institutions. We made a theoretical review of the concept of democracy and used survey data provided by Latinobarometro to evaluate variables that may explain the ranking of contemporary democracies in terms of their quality. The results showed that, from the standpoint of political institutions, the quality of democracy in Brazil has been evaluated positively, but from the point of view of their content and the effectiveness of its results, democracy has not reached more substantive qualitative measures.
\end{abstract}

Keywords: Democracy; Quality of Democracy; Support; Satisfaction; Trust. 


\section{Introdução}

Nos últimos anos institutos de pesquisa e pesquisadores têm buscado elaborar indicadores mais sofisticados para medir a qualidade da democracia, tanto em países industrializados como em desenvolvimento, de forma a estabelecer comparações entre eles. Avaliar e medir o desempenho das instituições democráticas não tem sido tarefa fácil diante da complexidade das variáveis envolvidas. No caso das recentes democracias da América Latina, o fato das eleições se constituírem no principal meio de acesso a cargos públicos, serem livres e periódicas, permite 0 alcance de indicadores democráticos mais positivos. Entretanto, índices dessa natureza, como por exemplo, o Índice de Democracia Eleitoral (IDE) e o Índice de Apoio à Democracia (IAD), elaborados pelo Programa das Nações Unidas (PNUD, 2004), não são capazes de medir dimensões importantes da prática democrática, como a qualidade institucional, a eficiência política, o comportamento dos dirigentes políticos, a satisfação dos cidadãos com a democracia, entre outras.

Nesse contexto, o objetivo do artigo é problematizar o modelo de democracia que vem se configurando no Brasil a partir de concepções teóricas vinculadas às pesquisas que buscam medir a qualidade da democracia de forma mais ampla, levando em conta dimensões de apoio e satisfação com a democracia, e confiança nas instituições políticas, além das garantias de liberdade, igualdade e direitos, a accountability vertical e horizontal, as formas de deliberação, representação e participação política, a resposta (outputs) dos governos às questões socioeconômicas. Para tanto, realizou-se revisão teórica acerca da concepção de democracia e utilizaram-se dados de pesquisas disponibilizadas pelo Latinobarômetro para sondar variáveis que podem explicar o ranking das democracias contemporâneas no âmbito de sua qualidade, estabilidade e legitimidade.

O artigo está estruturado em duas seções. A primeira apresenta uma breve discussão conceitual sobre a democracia a partir da literatura clássica e de pesquisas recentes sobre o tema, abordando suas vertentes teóricas minimalistas e maximalistas. A segunda seção apresenta alguns elementos do atual debate sobre a qualidade da democracia, posicionando o Brasil no ranking das democracias latino-americanas, de modo a explicitar os fatores que têm contribuído para as baixas pontuações da qualidade da democracia na região. As considerações finais apontam que, do ponto de vista da institucionalidade política, a qualidade da democracia no Brasil tem sido avaliada positivamente, mas do ponto de vista dos seus conteúdos e da efetividade de seus resultados, a democracia ainda não alcançou medidas qualitativas mais substantivas. 


\title{
Discussão conceitual de democracia ${ }^{1}$
}

As discussões sobre o conceito de democracia remontam às questões de representação, deliberação e participação, abordadas por autores clássicos da Ciência Política. Entre os teóricos elitistas destaca-se Joseph Schumpeter que definiu a democracia como um método de escolha de lideranças políticas, "certo tipo de arranjo institucional para se alcançarem decisões políticas legislativas e administrativas" (1984, p. 304). Dessa forma, as eleições são o acontecimento mais importante do regime democrático. O eleitorado, portanto, tem o papel de escolher os líderes que formarão o governo e, os líderes, por sua vez, disponíveis e com vocação política, competem pelo voto do povo em eleições livres e periódicas. Schumpeter argumenta que:

\begin{abstract}
Democracia significa apenas que o povo tem a oportunidade de aceitar ou recusar as pessoas designadas para governálos. Mas como o povo também pode decidir isso de maneira inteiramente não-democrática, temos de estreitar nossa definição, acrescentando mais um critério que defina o método democrático, ou seja, a livre competição entre líderes potenciais pelo voto do eleitorado. Ora, pode-se exprimir um aspecto dessa questão dizendo que a democracia é o controle sobre o político (SCHUMPETER, 1984, p. 355).
\end{abstract}

Como se vê, a teoria se concentra na escolha de líderes dentro de um universo reduzido de pessoas que têm a política como profissão. A função do povo, portanto, é a de escolher quem tomará as decisões. $E$, uma vez realizada a escolha, os mandatários têm ação desvinculada do eleitor, o qual continuará tendo o papel de "punir" ou "recompensar" os políticos através do voto retrospectivo. O sucesso das teorias elitistas na explicação da democracia consiste, segundo Avritzer (1999), em reunir críticas acerca da impossibilidade do exercício da "soberania popular" num contexto de sociedade de massas, e de propor um método racional de escolha de governantes onde a representação e o revezamento das elites no poder contribuem para a estabilidade do sistema democrático.

Nessa perspectiva de competição eleitoral, destacada por Schumpeter, surge uma nova corrente teórica de democracia: o pluralismo, cujo principal expoente é Robert Dahl. Em Poliarquia: participação e oposição (1991), o autor trata do processo de democratização pelos eixos da competição e da participação política, introduzindo a questão da responsividade como característica-chave da democracia. Os cidadãos devem ter, para tanto, três oportunidades plenas de

formular suas preferências; de expressar suas preferências a seus concidadãos e ao governo através da ação individual e da coletiva; de ter suas preferências igualmente consideradas

\footnotetext{
${ }^{1}$ As reflexões teóricas desta seção foram elaboradas com base na dissertação de mestrado de Dias (2012).
} 
na conduta do governo, ou seja, consideradas sem discriminação decorrente do conteúdo ou da fonte da preferência (DAHL, 1991, p. 25).

Além da responsividade, Dahl aborda a contestação pública e a inclusividade do sistema como variáveis para democratização. Quanto maior a participação e a contestação, mais inclusiva serão as poliarquias. O autor destaca a importância da existência de garantias constitucionais acerca das liberdades civis e políticas, do direito do voto e da formação de organizações políticas, além da presença de oposição ao governo e da alternância no poder. Enquanto os elitistas têm como foco o processo para a formação de governos, os pluralistas ampliam essa perspectiva defendendo a expressão legítima de diversos setores da sociedade.

$\mathrm{Na}$ tentativa de responder lacunas deixadas pelos pressupostos elitistas e pluralistas, emergiram novas teorias no debate acadêmico, entre elas a democracia deliberativa de Jürgen Habermas, e as contribuições de Carole Pateman acerca da democracia participativa, entre outros autores. Um dos conceitos centrais na teoria de Habermas é esfera pública, compreendida como um espaço de comunicação diferenciado do espaço formal estatal. É um espaço onde as pessoas, face a face, discutem e deliberam sobre questões políticas, podendo, por meio de processos institucionalizados, influenciarem o poder político. A esfera pública relaciona-se com a esfera privada, na medida em que aquela:

Retira seus impulsos da assimilação privada de problemas sociais que repercutem nas biografias particulares, neste contexto particular é sintomático constatar que, nas sociedades européias do século XVII e XVIII, se tenha formado uma esfera pública burguesa moderna, como "esfera das pessoas privadas reunidas e formando um público". Do ponto de vista histórico, o nexo entre esfera pública e privada começou a aparecer nas formas de reunião e de organização de um público leitor, composto de pessoas privadas burguesas, que se aglutinavam em torno de jornais e periódicos (HABERMAS, 1997, p. 98, grifos do autor).

A influência da esfera pública, dentro da qual se identificam e problematizam os assuntos de interesse geral, permite a inserção dos indivíduos nos processos decisórios, que continuam a exercer influência, além do momento do voto e da formação do governo. A deliberação nos espaços públicos faz com que as decisões ganhem ecos de legitimidade e deixem de ser meramente impositivas.

Na mesma linha de argumentação, Cohen (2000) endossa a importância da deliberação em detrimento do voto e da barganha, mas chama a atenção para as condições existentes para o processo deliberativo acontecer. De acordo com o autor são três condições da deliberação: decisão de uma agenda; proposição de soluções alternativas aos problemas da agenda; e consenso sobre uma das soluções. Destarte, os resultados somente 
poderão ser democraticamente legítimos "if and only if they could be the object of a free and reasoned agreement among equals" (COHEN, 2000, s./p.). Por isso há uma preocupação com medidas para atenuar os efeitos da distribuição desigual de recursos entre pessoas e grupos.

Em um cenário ideal, as decisões seriam resultado de um debate entre pessoas iguais e livres, fundamentado na racionalidade e na adoção de soluções propostas por meio do consenso. Cohen, ao tratar do que chama de novo igualitarismo, traça as razões para entender por que as arenas deliberativas são um avanço, em face das atuais condições de decisão do Estado, destacando o aspecto de aprendizado, da solução coletiva de problemas e da construção de solidariedade entre os debatedores (COHEN, 2000).

Na prática, a aplicação do modelo de democracia deliberativa nas sociedades contemporâneas enfrenta problemas relacionados às desigualdades e conflitos de interesses. Nesse sentido, Lüchmann (2005) argumenta que a busca por consensos coletivos pode gerar populismo (convencimento pelo líder), elitismo (determinados grupos convencem pelo poder político e econômico), coerção da maioria, entre outras. A autora chama a atenção para os conflitos inconciliáveis, como sendo o cerne principal das críticas às teorias deliberativas. Com efeito, os conflitos conciliáveis são hábeis de serem equacionados em um espaço público dialógico e plural, enquanto os inconciliáveis demandam o acionamento de mecanismos estratégicos, o que dá preponderância à ação estatal, na medida em que é essa esfera a que é especializada em agir dentro de tal lógica. E, de fato, várias experiências parecem corroborar essas críticas "[...] na medida em que são atravessadas por conflitos, por diferenças de interesses, de correlação de forças políticas e de recursos - simbólicos e materiais" (LÜCHMANN, 2005, p. 24).

Além dos enfoques da representação e da deliberação, a dimensão da participação possui relevância para a teoria democrática, especialmente porque rompe com a concepção tecnocrática e tradicional do Estado através do envolvimento dos cidadãos na esfera pública. A abordagem participativa demanda um novo modelo de gestão, e consequente valorização dos aspectos qualitativos no processo democrático, para além dos aspectos procedimentais e normativos (GUGLIANO, 2004). A perspectiva participativa dá ênfase à necessidade da democratização de outros espaços sociais, com destaque à indústria e ao caráter educativo do envolvimento do cidadão.

Com relação ao caráter educativo, Carole Pateman (1992, p. 65) argumenta que "a teoria da democracia participativa afirma que a experiência da participação, de algum modo, torna o indivíduo psicologicamente melhor equipado para participar ainda mais no futuro". Daí a necessidade de se democratizarem as estruturas de autoridade não governamental, como o local de trabalho. Apoiando-se em trabalhos empíricos, conclui que, "de maneira específica, o desenvolvimento de um senso de eficiência política parece depender do fato de sua situação de trabalho lhe proporcionar alguma perspectiva de participar das tomadas de decisões" (PATEMAN, 1992, p. 75). 
Entretanto, Pateman não aprofunda o conteúdo do conceito de democracia participativa, tampouco a forma em que ela poderia ser institucionalmente aplicada em lugar das democracias representativas (GONZÁLEZ, 2000).

De toda forma, a representação não inviabiliza a participação, pelo contrário, é a partir da participação eleitoral que a representação ganha vida, e a participação e o envolvimento político, por sua vez, contribuem para tornar a representação mais eficaz e mais transparente. Macpherson (1978) recoloca a questão da democracia participativa apregoando de que não se trata de fazê-la funcionar, mas de como atingi-la ou atingir considerável parcela dela. Por isso, a questão levantada diz respeito sobre quais mudanças serão necessárias para o alcance de uma democracia participativa nas sociedades contemporâneas. $O$ autor destaca algumas delas para o funcionamento desse modelo: mudança de consciência do povo, o qual deve deixar de ver-se como consumidor no mercado político para ter, de si, a visão de executor e desfrutador da execução e do desenvolvimento de sua própria capacidade; e mudanças em relação aos aspectos socioeconômicos, de modo a assegurar a coesão social num quadro de desigualdades.

Forma-se um círculo em torno desses requisitos: como alcançar maior participação sem uma mudança prévia na consciência do povo e nas condições de desigualdade social? Como efetivar mudanças na consciência do povo e nas condições de desigualdade sem um prévio aumento da participação? O que se observa na prática das sociedades é uma consciência cada vez maior para os custos da apatia política, especialmente em relação às questões do meio ambiente, da igualdade racial, e dos direitos das minorias. Nessa perspectiva, o referido autor propõe um modelo que concilia a democracia participativa com a estrutura da democracia representativa, a partir da dinâmica do modelo piramidal que se inicia na base, nos bairros, e nas comunidades através do envolvimento direto dos cidadãos nos fóruns e espaços de participação, avançando para a composição de delegados e representantes dentro dos Conselhos Municipais e do Orçamento Participativo, por exemplo.

Dessa forma, observa-se que o debate entre representação e participação nas democracias contemporâneas está pautado nas teorias elitistas, pluralistas e participacionistas, todas tendo como referência a participação política em graus e/ou modalidades diferentes. A primeira se atém à formação de governos através do sufrágio eleitoral, a segunda amplia a perspectiva eleitoral propondo poliarquias mais inclusivas, e a terceira defende a participação direta dos cidadãos nas decisões políticas, seja nos espaços formais e institucionalizados de participação ou nos informais, como passeatas, protestos, boicotes, petições. Essas últimas modalidades de participação, segundo Pippa Norris (2003) incorporam novas formas de expressão política, mobilização e envolvimento político. A autora argumenta que as agências tradicionais de ativismo político (partidos, sindicatos, associações, igrejas) convivem hoje com as agências modernas que se caracterizam por serem mais flexíveis e horizontais e por exigirem maior eficácia e transparência das ações governamentais. 
A próxima seção busca ampliar o debate conceitual da democracia confrontando com dimensões práticas da experiência democrática na América Latina nos últimos anos, tendo em vista situar o debate sobre a qualidade da democracia na região.

\section{Debate sobre qualidade da democracia ${ }^{2}$}

Ao longo dos últimos trinta anos, a experiência democrática na América Latina tem revelado que as regras do jogo democrático e os procedimentos poliárquicos (DAHL, 1991) têm sido respeitados e apoiados pela maioria da população. Dentre as características fundamentais da democracia contemporânea, como apontadas na seção anterior, destacam-se a realização e a institucionalização de eleições regulares, competitivas, livres, igualitárias, decisivas e inclusivas, a garantia de liberdades individuais e de direitos políticos, a existência de oposição política e a real chance de alternância de grupos no poder, liberdade de expressão e acesso a fontes alternativas de informação sobre os governos e a política em geral.

No intuito de ampliar o debate, parte da literatura questiona sobre a existência concreta das liberdades e dos direitos políticos no interior das democracias, primando para uma concepção mais substantiva e prática do que normativa. Nesse sentido, a democracia, objeto de reflexão da prática política,

Consiste, além do núcleo do regime e de sua própria democratização, na aquisição e amparo legal de direitos e liberdades, sustentados de forma mais ampla e mais sólida, que dizem respeito aos aspectos civis, sociais e culturais da cidadania - e também, é claro, à expansão de liberdades e direitos políticos (O’DONNELL, 2011, p. 253).

Na mesma linha de argumentação, Baquero (2011) destaca que o progresso democrático na região latino-americana depende, em parte, da consolidação de culturas políticas orientadas para comportamentos e atitudes democráticas, voltadas para a cooperação, responsabilidade e responsividade política, cujo objetivo é cobrar maior efetividade dos governos democráticos. De acordo com o autor,

A efetividade significa que não é suficiente instalar instituições democráticas. Elas precisam funcionar. É preciso garantir a independência do Poder Judiciário, e os partidos políticos necessitam desempenhar bem suas funções de representação, bem como as políticas sociais devem ser um reflexo do contrato social genuíno que inclua não somente a proteção dos direitos individuais, mas, sobretudo, a

\footnotetext{
${ }^{2}$ Esta seção tem como base as reflexões apresentadas no $8^{\circ}$ Encontro da Associação Brasileira de Ciência Política - ABCP, Gramado, RS: Determinantes do voto e qualidade da democracia no Nordeste do Brasil (AMORIM, 2012).
} 
solidariedade social com o objetivo de apoiar aos mais vulneráveis (BAQUERO, 2011, p. 19).

O referido contrato social não tem sido cumprido integralmente pelo Estado, a despeito do apoio político dispensado pela sociedade civil, via eleições e pagamento de impostos (EASTON, 1968). Nas democracias contemporâneas, o "rompimento" do pacto social tem sido expresso pelas contínuas práticas de corrupção na política, pela permanência de práticas clientelistas, personalistas e patrimonialistas, e pela crise de confiança nas instituições políticas e nos seus gestores públicos, o que tende a reforçar o estabelecimento de relações terciárias - relações diretas entre o Estado e a sociedade, sem a mediação das instituições políticas democráticas. Este tipo de relação desenvolve uma cultura política híbrida, caracterizada pela existência de normas democráticas que convivem com práticas conservadoras e autoritárias no interior do regime político.

A população, apesar de insatisfeita com a ausência de serviços públicos de qualidade, está cumprindo sua parte no contrato, de forma resignada e passiva. Esse dado é importante, pois, uma das dimensões da qualidade da democracia está relacionada à satisfação dos cidadãos com o desempenho do regime democrático, e nos últimos anos, observamos uma crescente insatisfação da população com a atuação das instituições políticas. Conforme Morlino (2010, p. 39), "em termos de responsividade, a legitimidade está relacionada à presença de atitudes e comportamentos do público em geral que confirmam a satisfação com a democracia existente".

Dessa forma, a referida literatura sugere que a avaliação da qualidade da democracia deve ser baseada em três dimensões: qualidade dos procedimentos, do conteúdo e dos resultados. A democracia que realiza eleições competitivas, regulares e limpas, que possui organizações partidárias e mecanismos de monitoramento sobre a eficácia das leis e das decisões governamentais (procedimentos), que garante igualdade política e respeito às liberdades civis e políticas (conteúdo), e que possui cidadãos satisfeitos com os resultados da democracia, alcança maior qualidade, legitimidade e estabilidade política. Esta última dimensão diz respeito à capacidade de resposta (outputs) do sistema político às demandas da sociedade. Apesar da dificuldade de estabelecer parâmetros de comparação entre os países para "medir" a qualidade da democracia, diante de diferentes contextos e realidades, há um esforço para desenvolver medidas quantitativas e qualitativas para analisar a democracia do ponto de vista mais prático e substantivo (DIAMOND e MORLINO, 2004).

No caso das democracias representativas, as instituições democráticas, bem como os mecanismos de accountability vertical e horizontal, são os principais objetos de análise da qualidade da democracia no tocante aos procedimentos. As eleições têm um importante papel no controle dos líderes políticos, especialmente pela oportunidade que o eleitor tem de avaliar o desempenho dos políticos e de votar ou não no candidato ao cargo público, punindo-o ou recompensando-o. A questão que se coloca é se o eleitor tem 
informação suficiente para exercitar tal ponderação. Outra forma de controle social é a chamada accountability horizontal, que se refere a instituições ou atores coletivos que têm o poder de controlar o comportamento dos governantes. Esse monitoramento é exercido pelo parlamento, pelos tribunais constitucionais, pelos órgãos de auditoria, pelos partidos políticos, pela mídia, pelos sindicatos e associações em geral (O'DONNELL, 2011).

Do ponto de vista institucional, é possível estabelecer parâmetros de comparação entre os países, em seus diferentes contextos sociopolíticos, situando-os numa escala de gradação entre "mais" ou "menos" democráticos. Nos últimos anos, diversos pesquisadores e institutos de pesquisa têm buscado criar indicadores para medir e avaliar o desempenho das instituições democráticas, de forma a estabelecer comparações entre os países, tendo em vista contribuir com propostas de aperfeiçoamento e melhoria das democracias.

A Fundação Konrad-Adenauer elaborou o Índice de Desenvolvimento Democrático da América Latina - IDD-Lat ${ }^{3}$, que permite comparar a evolução das instituições democráticas e o comportamento dos dirigentes políticos e da sociedade civil. Para efeito de cálculo foram considerados 31 indicadores agrupados a quatro dimensões: as condições básicas da democracia, que avalia a institucionalidade do regime democrático; o respeito aos direitos políticos e às liberdades civis, variável que avalia o desempenho do sistema democrático do ponto de vista da cidadania; a qualidade institucional e a eficiência política, que avalia o desempenho do sistema democrático do ponto de vista das instituições; e o exercício do poder efetivo para governar, que mede os esforços para a realização de políticas que assegurem o bem-estar social e o desenvolvimento econômico.

De acordo a pesquisa (INFORME IDD-LAT, 2009), os governos não estão gerando políticas capazes de responder as demandas sociais nas áreas prioritárias, como saúde, educação e habitação. Em relação à área econômica, os países da América Latina têm apresentado um alto nível de concentração de renda e um elevado índice de desigualdades e pobreza.

A "Democracy Ranking Association" é uma associação que publica anualmente o ranking das democracias contemporâneas, a partir da avaliação de variáveis políticas (direitos políticos, liberdades civis, liberdade de imprensa, índice de corrupção, alternância de partido político no governo), e variáveis não-políticas, como indicadores econômicos, igualdade de gênero, grau de conhecimento, condições da saúde e do meio ambiente. A fórmula conceitual do ranking tem como base as reflexões teóricas de Guillermo O'Donnell sobre a qualidade da democracia, que agrega direitos humanos e desenvolvimento socioeconômico e político ${ }^{4}$.

\footnotetext{
3 Para obter maiores informações sobre o aporte metodológico do índice consultar a página da web <http://www.idd-lat.org>.

4 Informações disponíveis no site: <http://www.democracyranking.org>. Fórmula: Quality of Democracy $=($ freedom + other characteristics of the political system $)+($ performance of the non-political dimensions).
} 
Gráfico 1 - Ranking Qualidade da Democracia - 2011 (scores)

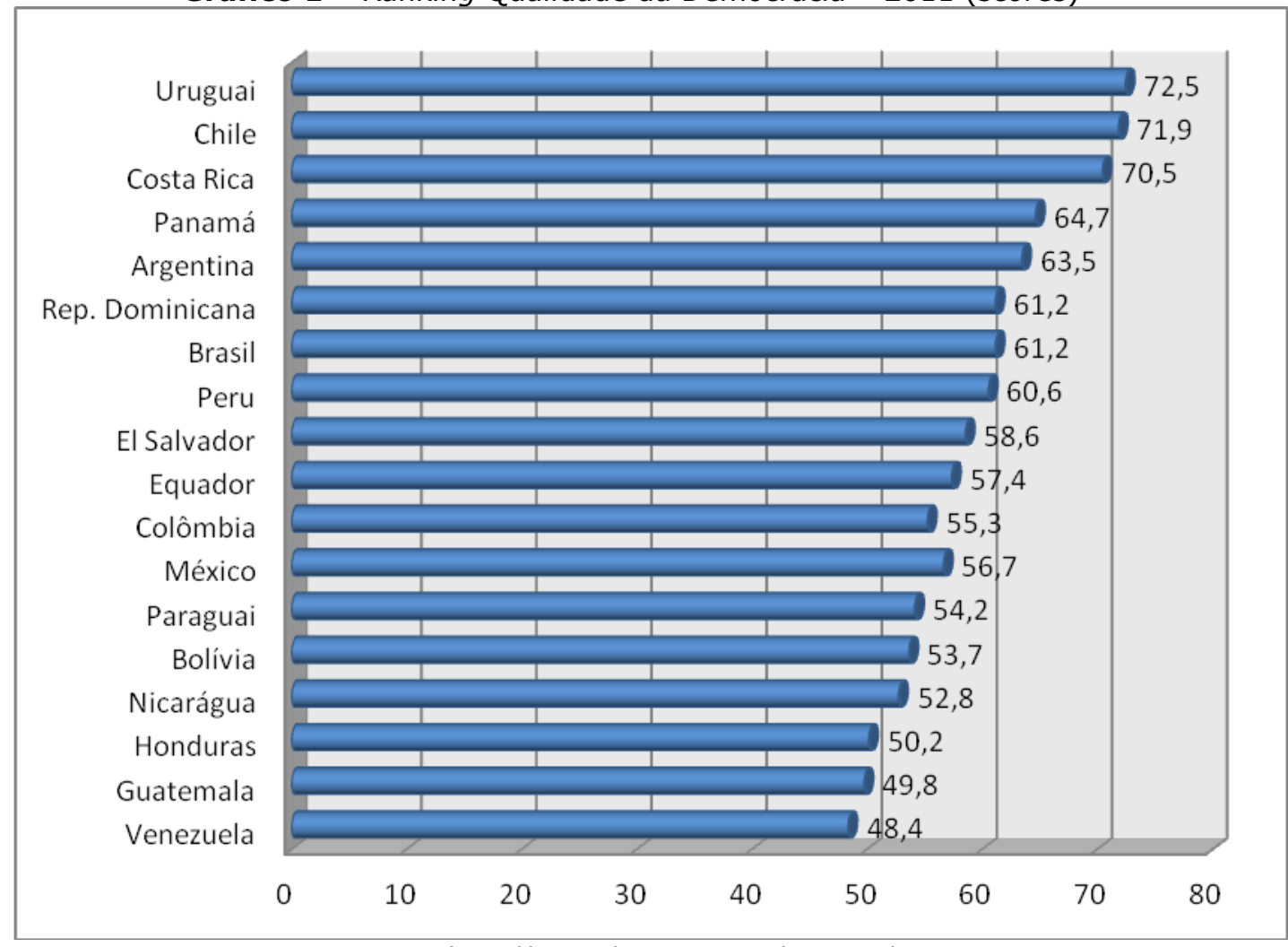

Fonte: <http://www.democracyranking.org/>.

O levantamento de dados foi realizado entre 2009 e 2010 em países classificados pela Freedom House como "livres" ou "parcialmente livres", portanto, Cuba e Haiti não aparecem no ranking. O Gráfico 1 mostra que o Uruguai, o Chile e a Costa Rica situam-se entre os mais democráticos da região, ao passo que a Guatemala e a Venezuela se posicionam como os menos democráticos. Por um lado, os indicadores políticos têm contribuído para uma melhor avaliação da democracia na região, entretanto, os crescentes índices de corrupção na política, a ocorrência de fraudes nas eleições e tentativas de golpes, bem como as desigualdades sociais e a pobreza são fatores que mantêm as pontuações baixas para a qualidade da democracia na América Latina, como observado no Gráfico 1.

Estudos têm acompanhado os modelos de democracia que vem se configurando entre os países latino-americanos desde os anos 1970. A experiência democrática na região revela uma gradativa consolidação dos procedimentos democráticos na América Latina. Smith e Ziegler (2009) examinaram as democracias latino-americanas a partir da abordagem proposta por Fareed Zakaria, enfocando a distinção entre democracias "liberais" e "iliberais", cujos parâmetros baseiam-se na existência (ou não) de eleições livres e justas, garantias constitucionais dos direitos e liberdades 
civis, e competição aberta. Democracias que realizam eleições periódicas, mas que se mostram injustas ou fraudulentas, associadas ao não cumprimento das leis, são caracterizadas como "iliberais".

Em alguns países são flagrantes as violações aos direitos civis, a censura aos meios de comunicação, a arbitrária violência policial, e a falta de alternância política entre os partidos políticos, a exemplo do Paraguai que manteve a hegemonia do Partido Colorado por mais dezenove anos mesmo depois da transição democrática e que atualmente sofre com a instabilidade política no país. Trata-se, portanto, de democracias com características híbridas, pois a normatividade institucional tem convivido com uma cultura política conservadora e autoritária, com precário apoio específico e substantivo.

As pesquisas de opinião, realizadas nos últimos anos, fornecem importantes subsídios sobre a cultura política latino-americana e permitem um estudo cada vez mais sistematizado e comparativo dos aspectos substantivos da democracia entre os países, revelando uma dinâmica sobre a relação entre o desempenho das instituições políticas e o grau de satisfação dos cidadãos acerca da democracia. As primeiras pesquisas realizadas pelo Latinobarômetro, em 1995, incluíram oito países: Argentina, Brasil, Chile, México, Paraguai, Peru, Uruguai e Venezuela. As amostras eram probabilísticas em alguns países e por cotas em outros, variando entre 560 a $1200 \operatorname{casos}^{5}$. A pergunta sobre a preferência do regime político era importante, naquele momento, para medir o impacto das transições políticas ocorridas na região, especialmente nos anos 1980 (AMORIM, 2011). O Gráfico 2 apresenta dados relativos à preferência pelo regime democrático e sobre a importância atribuída aos partidos políticos na democracia, numa perspectiva temporal, em dois países vizinhos da América Latina.

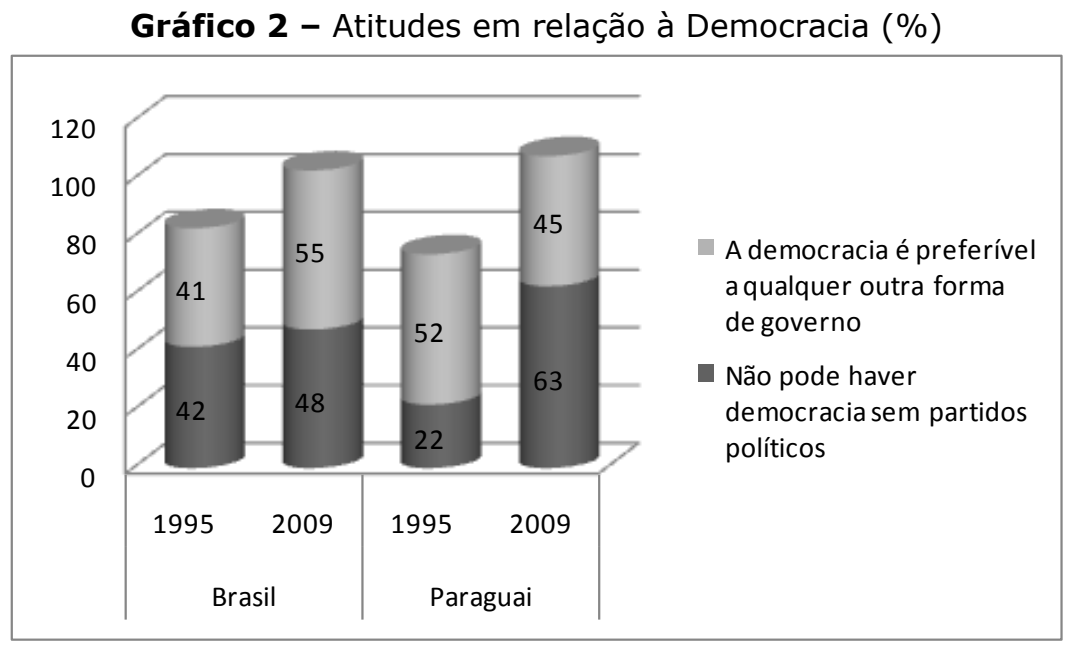

Fonte: Latinobarômetro (1995 e 2009).

\footnotetext{
${ }^{5}$ Maiores informações sobre o desenho amostral consultar o site <www.latinobarometro.org $>$.
} 
Tanto o caso brasileiro quanto o paraguaio expressam um baixo apoio normativo à democracia no período apresentado. Não podemos negar que este apoio é essencial para a construção de normas democráticas, ainda que não suficiente para a consolidação das instituições políticas. Por outro lado, o apoio específico é importante porque reflete um apoio incondicional ao sistema político através da participação e do envolvimento político dos cidadãos, como alertou David Easton nos anos 1960.

Em termos comparativos, observa-se no Gráfico 2 pequena evolução no apoio à democracia no Brasil (de $41 \%$ para $55 \%$ em 2009), como também na atribuição da importância aos partidos políticos no processo político democrático (de $42 \%$ para $48 \%$ ). Apesar dos baixos percentuais, o crescimento de uma percepção positiva dos brasileiros pode ser explicada a partir dos índices de aprovação dos últimos governos, pela sua atuação na área econômica (estabilidade econômica) e na área social (mais investimentos em programas sociais). No caso do Paraguai o declínio no apoio normativo à democracia (de $52 \%$ para $45 \%$ ) é conflitante com a afirmativa de que não pode haver democracia sem partidos políticos (de $22 \%$ para $63 \%$ em 2009). Os dados mostram um aumento de atitude democrática em relação aos partidos políticos paraguaios nestes últimos anos, a despeito da crise política. Os partidos ganharam força política especialmente no final dos anos 1990, quando a competição eleitoral se dá de forma mais democrática, e em 2009 os partidos políticos receberam uma avaliação mais positiva por parte dos paraguaios.

Ao lado dos indicadores de apoio ao regime democrático, cabe examinar também o nível de satisfação da população com o funcionamento da democracia. A questão suscitada é: a adesão à democracia é resultado do desempenho de suas instituições e do grau de satisfação com a democracia? O Gráfico 3 apresenta a soma das respostas "Muito Satisfeito" e "Satisfeito" com o desempenho da democracia em ambos os países, numa escala temporal. 
Gráfico 3 - Satisfação com a Democracia (\%)

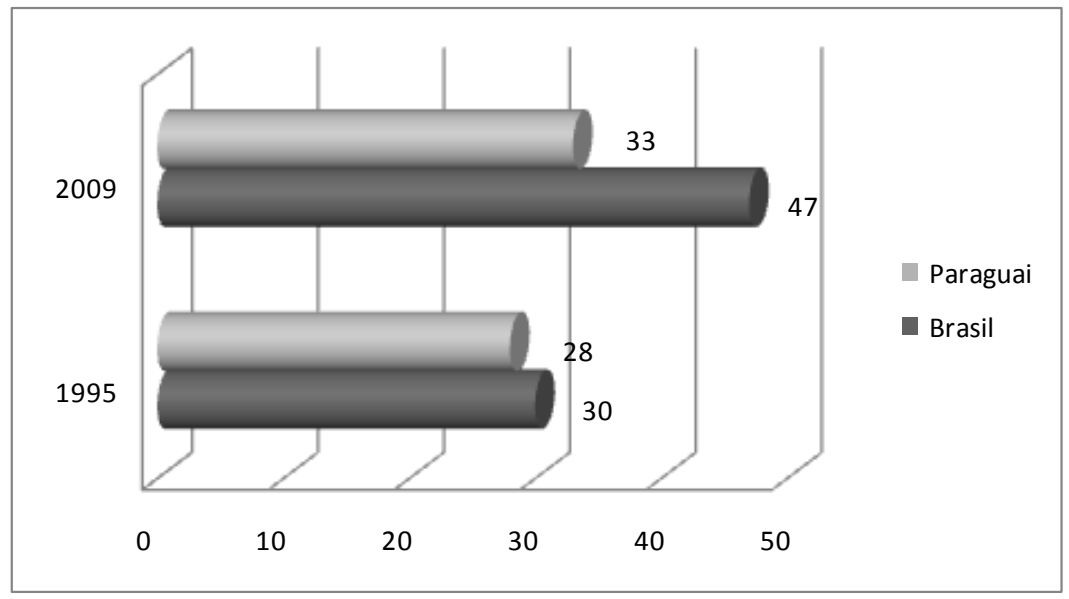

Fonte: Latinobarômetro (1995 e 2009).

Os dados revelam pouca alteração entre os anos de 1995 e 2009, em ambos os países, que mantêm baixos percentuais de satisfação com a democracia. O que explica a insatisfação dos cidadãos em relação ao desempenho do regime democrático? O Paraguai é um dos menores países da América Latina, com uma população de seis milhões de habitantes, e apesar de ser um dos maiores produtores de soja da região, é um dos países mais pobres, ocupando a $98^{a}$ posição de desenvolvimento humano entre 192 países, com um Índice de Desenvolvimento Humano de 0,752 (PNUD, 2008). Acrescente-se a isso que o país se tornou uma das principais áreas de atividades de contrabando, lavagem de dinheiro e crime organizado na região. De modo que a insatisfação dos cidadãos paraguaios com o desempenho do regime democrático advém deste quadro de crise social, inalterado desde a transição e que tem sido enfrentado pelos últimos governos.

No caso do Brasil, o Gráfico 3 apresenta um pequeno aumento no nível de satisfação entre os brasileiros (de $30 \%$ para $47 \%$ em 2009), assim como mostrou o Gráfico anterior em relação ao apoio à democracia. Uma das explicações possíveis para essa avaliação mais positiva está relacionada ao investimento dos governos democráticos nas áreas social e econômica, no sentido de responder às demandas da população com programas sociais, e ao mesmo tempo garantir maior estabilidade para a economia brasileira. Essa oscilação de percentuais entre o Brasil e o Paraguai no tocante à satisfação com o regime expressa uma avaliação circunstancial que envolve examinar a eficácia da atuação dos governos democráticos, especialmente no atendimento às demandas sociais.

De acordo com Moisés e Carneiro (2008), as dimensões relativas à satisfação com a democracia e a confiança nas instituições fazem parte de um mesmo conjunto de atitudes políticas, de modo que, 
quando prevalece a ineficiência ou a indiferença institucional diante de demandas para fazer valer direitos assegurados por lei ou generalizam-se práticas de corrupção, de fraude ou de desrespeito ao interesse público, instala-se uma atmosfera de suspeição, de descrédito e de desesperança, comprometendo a aquiescência dos cidadãos à lei e às estruturas que regulam a vida social; floresce, então, a desconfiança e o distanciamento dos cidadãos da política e das instituições democráticas (MOISÉS e CARNEIRO, 2008, p. 39).

Quando os referidos autores examinam a evolução no tempo das variáveis para o caso da América Latina, observam que a adesão ao regime democrático é alta, ao passo que os percentuais de confiança e de satisfação com a democracia mantêm-se abaixo de 40\%. De forma mais simplificada, busca-se apresentar aqui essas variáveis para o caso do Brasil e Paraguai onde são encontrados resultados semelhantes e preocupantes do ponto de vista da consolidação democrática. O Gráfico 4 ilustra a evolução da satisfação e da confiança política entre 1995 e 2005.

Gráfico 4 - Evolução da Satisfação com a Democracia e da Confiança nos Partidos Políticos - Brasil - 1995-2005 (\%)

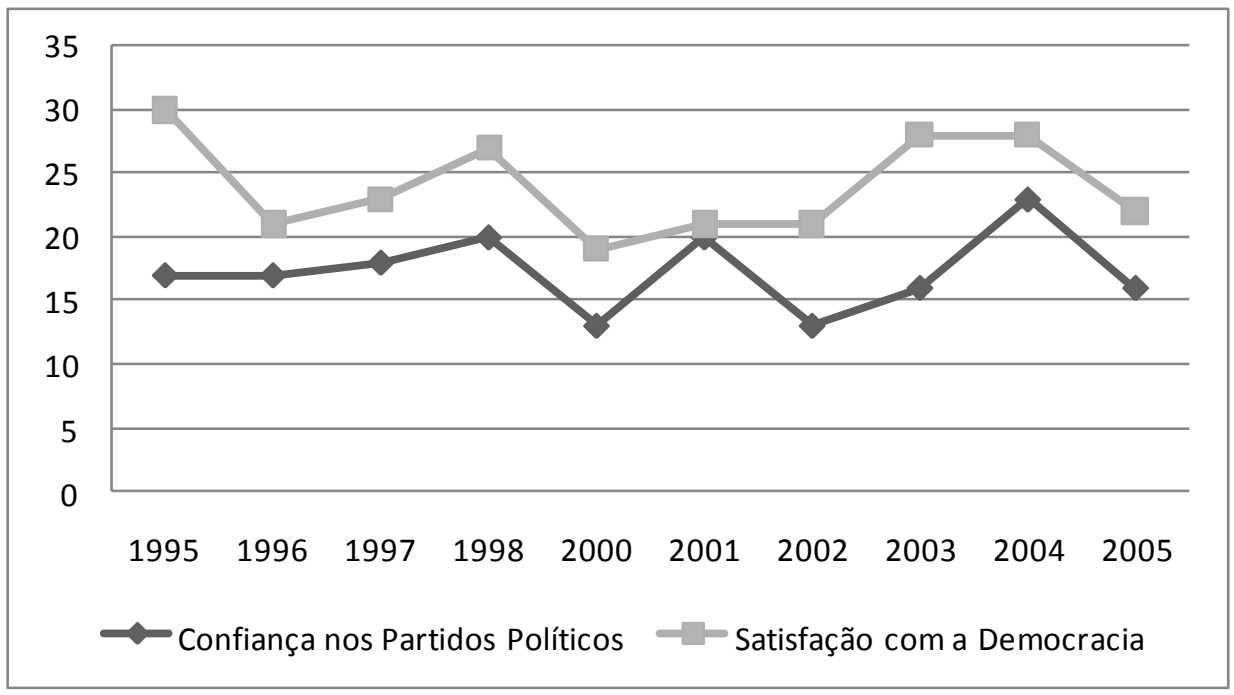

Fonte: Latinobarômetro (1995-2005).

OBS: Para a variável Satisfação com a Democracia foram consideradas apenas as respostas: "Muito Satisfeito" e "Satisfeito". Para a variável Confiança nos Partidos Políticos foram consideradas apenas as respostas: "Muita confiança" e "Alguma confiança".

De acordo com o Gráfico 4, as curvas das duas variáveis seguem paralelamente, com poucas alterações, de modo que nem a satisfação com a democracia e nem a confiança nos partidos ultrapassam os $30 \%$ no Brasil ao longo desses últimos dez anos. Desde a transição política o país vivencia a alterância do poder, numa competição política estável, seguindo para um 
regime democrático consolidado. Entretanto, os partidos políticos, historicamente considerados importantes canais de mediação e de represenação política, têm recebido os maiores percentuais de desconfiança no Brasil. Esse dado levanta questionamentos sobre a qualidade da democracia no país.

Segundo Moisés e Carneiro (2008), a razão para confiar está diretamente relacionada aos princípios éticos e normativos das instituições, ou seja, o cidadão avalia o desempenho das instituições e o comportamento dos seus gestores políticos. Esses indicadores expressam um descontentamento da população diante da situação econômica, da incapacidade dos governos em responderem aos problemas sociais, da má qualidade dos serviços públicos e da impunidade frente à corrupção generalizada na política.

Se por um lado, a confiança política está relacionada com o desempenho das instituições e com a avaliação do comportamento dos gestores públicos, a razão para participar está associada ao sentimento de eficácia política ou competência política subjetiva. Um sentimento no qual os indivíduos acreditam que podem influenciar nas decisões políticas. A análise de Almond e Powell Jr. (1972) revela que os cidadãos mostram-se mais dispostos a participar quando acreditam que suas ações e seus objetivos serão alcançados. Os dados aqui analisados evidenciaram que os brasileiros e os paraguaios convivem com uma cultura política híbrida, na qual coexistem elementos autoritários e democráticos. O processo de socialização política vivenciado na região foi marcado pela repressão e não pela liberdade de participação, pela apatia e desconfiança, e não pela crença nos valores democráticos. O reconhecimento de que a participação popular e a confiança política sintetizam valores da cultura política democrática demonstra a importância de investigações mais aprofundadas sobre a democracia na América Latina.

\section{Considerações Finais}

Este artigo buscou situar o debate sobre a qualidade da democracia no Brasil à luz da teoria democrática e da perspectiva mais prática e substantiva da democracia. Observamos que existem avanços significativos na América Latina no tocante às garantias político-institucionais, especialmente em períodos eleitorais. De fato, está instituído nos países um tipo de arranjo institucional para a escolha de lideranças políticas, tal como apregoado por Schumpeter. Por sua vez, existe a a abertura para a participação política, a presença de oposição/contestação, e consequente alternância do poder na maioria dos países da região, como prevê a teoria pluralista de Dahl.

Por um lado, os partidos políticos estão desacreditados, mas por outro, espaços de participação como os Conselhos e os Fóruns deliberativos têm sido ocupados por parte da população interessada. Apesar da institucionalidade política, encontramos em diversos países da região situações de instabilidades e crises associadas à corrupção e às desigualdades sociais. A América Latina está entre as regiões com maiores níveis de concentração de renda e 
elevados índices de desigualdades e pobreza. Em 2010, o Brasil posicionavase como o país mais desigual no ranking da região, onde os $10 \%$ mais ricos concentram $51 \%$ da renda. E em países como Nicarágua, Panamá e Paraguai, os $10 \%$ mais ricos consumiam mais de $40 \%$ dos recursos, apresentando também grande disparidade entre ricos e pobres (ONU, 2010).

A análise realizada verificou que a democracia que se configura nos países da América Latina se aproxima do modelo intitulado pela literatura de "democracia iliberal", aquela que se baseia na existência de eleições periódicas e garantias constitucionais, mas que em determinados contextos se mostram injustas e fraudulentas, com a presença de altos índices de violência e delinquência, violação de direitos humanos e civis, e resquícios de autoritarismo e conservadorismo nas condutas dos líderes políticos democráticos. No caso do Brasil, que alcançou uma qualidade média de democracia, está mais próximo de uma democracia liberal, procedimental e representativa, com dimensões participativas. Mas a democracia brasileira ainda precisa enfrentar muitos problemas antes de ser considerada política, social, econômica e culturalmente consolidada.

\footnotetext{
Maria Salete Souza de Amorim é Doutora em Ciência Política pela Universidade Federal do Rio Grande do Sul (UFRGS) e professora do Programa de Pós-Graduação em Ciências Sociais da Universidade Federal da Bahia (UFBA).

E-mail: saleteamorim@uol.com.br
}

Rodrigo Rodriguez Dias é Mestre em Ciências Sociais pela Universidade Estadual do Oeste do Paraná (UNIOESTE), professor na Faculdade Sul Brasil (FASUL) e Juiz da Vara da Infância, Juventude e Família de Toledo-PR.

E-mail: rodrigues_dias@uol.com.br

\section{Referências}

ALMOND, Gabriel; POWELL Jr., G. Bingham. Uma Teoria de Política Comparada. Rio de Janeiro: Zahar, 1972.

AMORIM, Maria Salete S. de. Democracia e Cultura Política em perspectiva comparada: Brasil e Paraguai. In: BAQUERO, Marcello (Org). Cultura(s) Política(s) e Democracia no Século XXI na América Latina. Porto Alegre: Ed. UFRGS, 2011. p. 119-140.

- Determinantes do voto e qualidade da democracia no Nordeste do Brasil. In: Encontro Nacional da Associação Brasileira de Ciência Política ABCP, 8., Gramado, 2012.

AVRITZER, Leonardo. Teoria democrática, esfera pública e participação local. Sociologias, Porto Alegre, ano 1, n. 2, p. 18-43, jul.-dez. 1999. 
BAQUERO, Marcello. A cultura política na agenda da democratização na América Latina. In: (Org). Cultura(s) Política(s) e Democracia no Século XXI na América Latina. Porto Alegre: Ed. UFRGS, 2011. p. 13-23.

COHEN, Joshua. Deliberation and democratic legitimacy. 2000. Disponível em: <http://philosophyfaculty.ucsd.edu/faculty/rarneson/JCOHENDELIBERATIVE\% 20DEM.pdf>. Acesso em: 22 jul. 2010.

DAHL, Robert Alan. Poliarquia: participação e oposição. São Paulo: Edusp, 1991.

DIAMOND, Larry; MORLINO, Leonardo. The quality of democracy. Center on Democracy, Development, and The Rule of Law Stanford Institute on International Studies, (CDDRL Working Papers), sept. 2004. n.20. Disponível em: <http://cddrl.stanford.edu/>. Acesso em: 01 set. 2012.

DIAS, Rodrigo Rodrigues. A ação efetiva do Conselho Municipal dos Direitos da Criança e do Adolescente (CMDCA) de Toledo/PR: vinculação e prioridade. 2012. 205 f. Dissertação (Mestrado em Ciências Sociais) - Programa de PósGraduação em Ciências Sociais, Universidade Estadual do Oeste do Paraná, Toledo, 2012.

EASTON, David. Uma teoria de análise política. Rio de Janeiro: Zahar Editores, 1968.

GONZÁLEZ, Rodrigo. Democracia e Conselhos de Controle de Políticas Públicas: uma análise comparativa. 2000. 327 f. Tese (Doutorado em Ciência Política) - Programa de Pós- Graduação em Ciência Política, Universidade Federal do Rio Grande do Sul, Porto Alegre, 2000.

GUGLIANO, Alfredo. Democracia, participação e deliberação. Contribuições ao debate sobre possíveis transformações na esfera democrática. Civitas, Porto Alegre, v. 4, n. 2, p. 258-283, jul.-dez. 2004. Disponível em: <http://revistaseletronicas.pucrs.br/ojs/index.php/civitas/article/viewFile/14/ 1616>. Acesso em: 21 jul. 2010.

HABERMAS, Jürgen. Direito e democracia: entre faticidade e validade. Rio de Janeiro: Tempo Brasileiro, 1997.

LÜCHMANN, Lígia Helena. Os sentidos e os desafios da participação. In: Congresso Brasileiro de Sociologia, 12., Belo Horizonte, 2005.

MACPHERSON, Crawford. A democracia liberal. Rio de Janeiro: Zahar, 1978. 
MOISÉS, José Álvaro; CARNEIRO, Gabriela Piquet. Democracia, desconfiança política e insatisfação com o regime: o caso do Brasil. Opinião Pública, Campinas, v. 14, n. 1, p. 1-42, jun. 2008.

MORLINO, Leonardo. Teoria da democratização, qualidade da democracia e pesquisa de opinião: ainda em "mesas separadas"? In: MOISÉS, José Álvaro (Org). Democracia e confiança: por que os cidadãos desconfiam das instituições públicas? São Paulo: Edusp, 2010. p. 23-44.

NORRIS, Pippa. Young People \& Political Activism: From the Politics of Loyalties to the Politics of Choise? 2003. Disponível em: <http://ksghone.harvard.edu/ pnorris>. Acesso em: 01 set. 2012.

O'DONNELL, Guillermo. Democracia, agência e Estado. Teoria com intenção comparativa. São Paulo: Paz e Terra, 2011.

ONU. Informe sobre Desarrollo Humano 2010. Edición del Vigésimo Aniversario. La verdadera riqueza de las naciones: Caminos al desarrollo humano. 2010. Disponível em: <http://hdr.undp.org/en/media/HDR_2010_ ES_Complete_reprint.pdf>. Acesso em: 01 set. 2012.

PATEMAN, Carole. Participação e teoria democrática. Rio de Janeiro: Paz e Terra, 1992.

PNUD. Relatório do Programa das Nações Unidas para o Desenvolvimento - La Democracia en America Latina: Para una democracia de ciudadanas y ciudadanos. 2004. Disponível em: <http://www2.ohchr.org/spanish/issues/ democracy/costarica/docs/PNUD-seminario.pdf>. Acesso em: 01 set. 2012.

. Informe sobre Desarrollo Humano 2007-2008. La lucha contra el cambio climático: Solidaridad frente a un mundo dividido. 2008. Disponível em: <http://www.pnud.org.br/hdr/arquivos/rdh20072008/hdr_20072008_pt_ complete.pdf>. Acesso em: 01 set. 2012.

SCHUMPETER, Joseph. Capitalismo, socialismo e democracia. Rio de Janeiro: Zahar Editora, 1984.

SMITH, Peter; ZIEGLER, Melissa. Democracias liberal e iliberal na América Latina. Opinião Pública, Campinas, v. 15, n. 2, p. 356-385, nov. 2009.

Texto recebido em 01/09/2012.

Aprovado em 01/11/2012. 